\title{
Application of glue machinery repairs in Arctic conditions
}

\author{
Alexander Konoplin ${ }^{1}$, Natalia Baurova ${ }^{1, *}$, and Sergei Abrakov ${ }^{1}$ \\ ${ }^{1}$ Moscow Automobile and Road Construction State Technical University (MADI), 125319, Moscow, \\ Leningradskii pr.64, Russia
}

\begin{abstract}
In this article the possibility of repairing machines in subzero temperatures is evaluated. Standards for determination of polymer materials frost resistance and technical requirements for glues used for repairing in Arctic conditions are reviewed. The possibilities of performing separate technological transitions and operations during repair in conditions of exposure to subzero temperatures are considered. The necessity of technology adjustment and special attention to the interoperational quality control during repair work in the Arctic is shown.
\end{abstract}

At present, the whole world pays great attention to the Arctic coast development, mining operations deployment, appropriate northern sea route security points creation. At the same time, Arctic zone and related infrastructure dynamic evolution is impossible without a development of technological methods of assembling and repairing machinery in the Arctic.

It is known that the operational conditions are playing a crucial role in the development of technological processes for machinery assembly and repair as well as in the selection of appropriate materials. They must be taken into account when it comes to materials selection for the repair technological process implementation. The development and implementation of modern, reliable technological methods of assembling and repairing vehicles adapted to the Arctic conditions is one of the main areas of the of modern machine building evolution. The most promising technologies that can be adapted to arctic conditions are glue assembly technologies (gluing, glue welding, glue riveting, etc.).

Adhesive assembly technologies are widely used in manufacturing and maintenance of cars, road construction machines and building structures. The main drawback of compounds obtained by using traditional assembly methods (welding, riveting, bolting) are high stress concentration (which leads to a decrease of fatigue endurance), low corrosion resistance and low joints' sealing capacity [1]. To overcome these drawbacks, polymer materials that allow creating glue-mechanical compounds are widely used in repair work lately [2]. In addition to the sealing capacity and corrosion resistance improvement, the use of adhesive assembly technology provides an optimal structures' strength and deformation characteristics combination [3] and the operation possibility under a long-term exposure to subzero temperatures.

\footnotetext{
*Corresponding author: nbaurova@mail.ru
} 
It is known that polymer materials have a partial or total loss of performance at low temperatures, i.e. limited frost resistance $[2,4]$. Therefore, the implementation of adhesive assembly technologies in Arctic requires a special attention to the frost resistance of the used materials.

Frost resistance is the ability of polymer materials to retain initially specified physical and mechanical properties and operating abilities at temperatures below the glass transition level (for amorphous polymers) or below the brittleness temperature (for crystallized polymers) $[3,5]$. Depending on the requirements for a material (operational conditions, initial properties), the frost resistance criteria can be different. For example, frost resistance for glassy polymers is the absence of brittleness, and for high-elastic polymers (along with the absence of brittleness), the main thing is high elasticity maintenance. In other words, for high elastic polymers, the temperature limit of frost resistance is the glass transition temperature, whereas for glassy polymers it's the temperature is brittleness.

There are a number of standardized polymer materials frost resistance estimating methods, which differ by the form of applied load and by test results evaluating methods. Main international frost resistance determination standards of polymeric materials are presented in table 1 [6].

Table 1. Main international frost resistance determination standards of polymeric materials

\begin{tabular}{|l|l|l|}
\hline \multicolumn{1}{|c|}{ Number } & \multicolumn{1}{|c|}{ Name } & \multicolumn{1}{|c|}{ Note } \\
\hline ASTM D2137-11 & $\begin{array}{l}\text { Standard determination methods } \\
\text { of rubber properties - brittleness } \\
\text { temperature of elastic polymers } \\
\text { and surface-coated materials }\end{array}$ & $\begin{array}{l}\text { These testing methods include the } \\
\text { determination of the temperature, at } \\
\text { which rubber can be vulcanized and } \\
\text { rubber-coated materials can suffer } \\
\text { certain shock loads without cracking } \\
\text { or breaking down }\end{array}$ \\
\hline ASTM D1790-08 & $\begin{array}{l}\text { Standard determination method of } \\
\text { plastic plates' brittleness } \\
\text { temperature using shock loads }\end{array}$ & $\begin{array}{l}\text { This method allows to determine the } \\
\text { temperature at which a 1 mm } 0.040 \\
\text { inch) or less thick plastic plate } \\
\text { demonstrates brittle fracture under } \\
\text { shock loads in certain conditions }\end{array}$ \\
\hline GOST 22346-77 & $\begin{array}{l}\text { Elastic cellular plastics. Freeze- } \\
\text { proof coefficient determination } \\
\text { method. }\end{array}$ & $\begin{array}{l}\text { Sets up freeze-proof coefficient } \\
\text { determination method. This method } \\
\text { suggests measuring and comparing } \\
\text { sample's compressive deformation } \\
\text { under a certain load and its load with } \\
\text { a certain deformation }\end{array}$ \\
\hline GOST 16783-71 & $\begin{array}{l}\text { Plasics. Loop-folded sample's } \\
\text { brittleness determination method. }\end{array}$ & $\begin{array}{l}\text { This method considers plastics with } \\
\text { brittleness temperature lower than } \\
\text { normal and sets up the way to } \\
\text { determine the brittleness temperature } \\
\text { of a loop-folded sample not thicker } \\
\text { than 0.5 mm. }\end{array}$ \\
\hline GOST 16782-92 & $\begin{array}{l}\text { Plastics. Brittleness temperature } \\
\text { determination method on impact. }\end{array}$ & $\begin{array}{l}\text { Determines the temperature at which } \\
\text { notched and non-notched samples } \\
\text { break down with 50\% probability. }\end{array}$ \\
\hline
\end{tabular}

Technical literature pays a lot of attention to studies of adhesive and polymer composite materials' properties in prolonged exposure to subzero temperatures. In [3, 7-9] some of the fundamental problems associated with ensuring a given quality of adhesive and composite materials were considered. However, in these and many other works, researchers study the properties of materials, but not their application technology. 
Traditionally, standard technological processes are used, all operations of which are carried out only at room temperature. With this approach, the determination of subzero temperatures effect on the quality of technological operations is not possible, since gluing is carried out and adhesive joints are hardened in standard conditions, and only then the effect of subzero temperatures on their properties is studied.

In Arctic conditions, many types of repair works, as, for example, body parts repair, box-type space constructions assembly, or pipe lines leakage elimination, are carried out in field conditions with no possibility of placing machines in positive temperature. So, the adaptation of existing repair technologies to Arctic conditions requires some special attention.

This research aims to evaluate glue repair feasibility in subzero temperatures.

In this case, besides of glue's frost-proof properties, ones of the joint made with this glue should be taken into account. Glue joint's frost tolerance is the lowest temperature, at which glue joint keeps its usability under a constant load. In other words, frost tolerance defines the lowest level of ploymer materials'and joints' continuous usability [4].

First of all, to develop a technical process of making glue mechanical joints (gluing, glue welding, glue riveting) in subzero temperatures, it's necessary to identify if a unit (a joint) is properly prepared and to choose a compound that meets all of the requirements. Such an evaluation must have defined technical requirements for polymers, which remain operational for long periods of time at below freezing temperatures. This evaluation is to be carried out in below freezing working condition. Table 2 demonstrates viscosity requirements for glue. In order to properly compare types of glues that have different viscosities (acrylic, silicate and epoxy) table 2 demonstrates acceptable viscosity percentages, instead of actual viscosity values.

Table 2. Glue materials viscosity requirements

\begin{tabular}{|c|c|}
\hline $\begin{array}{c}\text { Viscosity (Pa・s) at } \\
\text { temperature }\left({ }^{\circ} \mathbf{C}\right)\end{array}$ & $\begin{array}{c}\text { Maximum viscosity value, } \\
\mathbf{\%}\end{array}$ \\
\hline+20 & 100 \\
\hline+5 & 95 \\
\hline 0 & 95 \\
\hline-10 & 90 \\
\hline-30 & 70 \\
\hline
\end{tabular}

For the best effect in below freezing conditions, the viscosity of glues should not exceed the base value by more than $30 \%$, which corresponds to the viscosity levels of glue reached during the initial gel formation. A further decrease in temperature would reduce viscosity even more, requiring the use of special instruments for the preparation and application of the glue.

When choosing the right glue for use in arctic conditions, one must take into account the list of tasks the glue is designed to acheive. It is also best to select a glue that exceeds the technical requirements. This margin should be no less than $20 \%$ [9].

When is gomes to the quality of gluing, an qually important factor is the kinetic process in glue polymerization. Not all glues are even capable of curing in below freezing temperatures, and the speed at which curing occurs is significantly lower than curing at room temperature.

The evaluation of different glue's effectiveness in below freezing temperatures can be carried out using an expert method. The results of such an evaluation are presented in table 3.

The table 3 uses the following key:

- $\quad$ «+» marking indicates a capability for the use of standard equipment; 
- $\quad$ «-» marking indicates that standard equipment cannot be implemented or that the technological process cannot be carried outn altogether;

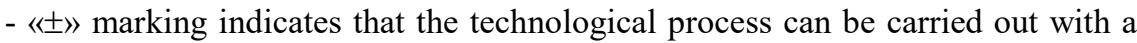
number of limitations.

Table 3. Expert evaluation results that define maintenance technology's frost endurance

\begin{tabular}{|c|c|c|c|c|}
\hline \multirow[t]{2}{*}{ № } & \multirow[t]{2}{*}{$\begin{array}{l}\text { Technological } \\
\text { operations names }\end{array}$} & \multirow[t]{2}{*}{ Technological transitions names } & \multicolumn{2}{|c|}{$\begin{array}{c}\text { Technological transition } \\
\text { capability }\end{array}$} \\
\hline & & & $\begin{array}{c}\text { room } \\
\text { temperature }\end{array}$ & $\begin{array}{c}\text { below } \\
\text { freezing } \\
\text { temperature }\end{array}$ \\
\hline 1 & $\begin{array}{l}\text { Preparation of } \\
\text { working } \\
\text { surfaces }\end{array}$ & $\begin{array}{l}\text { Smoothing of working surfaces using } \\
\text { hand instruments }\end{array}$ & + & \pm \\
\hline \multirow[t]{2}{*}{2} & \multirow{2}{*}{$\begin{array}{l}\text { Cleaning of } \\
\text { working } \\
\text { surfaces prior } \\
\text { to gluing. }\end{array}$} & $\begin{array}{l}\text { De-greasing of surfaces and drying } \\
\text { of solvents. }\end{array}$ & + & - \\
\hline & & Hand cleaning and de-greasing & + & - \\
\hline \multirow[t]{2}{*}{3} & \multirow{2}{*}{$\begin{array}{l}\text { Preparation of } \\
\text { adhesive } \\
\text { compounds }\end{array}$} & Weighing of glue components & + & \pm \\
\hline & & Mixing of glue components & + & \pm \\
\hline 4 & \multicolumn{2}{|c|}{ Application of glue to working surfaces } & + & \pm \\
\hline \multirow[t]{2}{*}{5} & \multirow{2}{*}{$\begin{array}{l}\text { Connection of } \\
\text { working surfaces }\end{array}$} & Setting the surfaces & + & \pm \\
\hline & & Fixation of the working surfaces & + & \pm \\
\hline 6 & \multicolumn{2}{|l|}{ Curing of glue } & + & - \\
\hline 7 & Quality control & $\begin{array}{l}\text { Visual seam quality control for the } \\
\text { detection of pores }\end{array}$ & + & + \\
\hline
\end{tabular}

Let us take a look at some of the specifics of gluing under below freezing working conditions.

Firstly, the surfaces that are to be glued undergo a mechanical abrasive treatment in order to remove any irregularities in the surfaces might contain. Usually, this procedure is carried out by hand. The main limitations in this process are the characteristics of the tools used.

Regular de-greasing procedures (such as solvent vapor treatment) cannot be carried out in arctic conditions. Considering the fact that de-greasing is a key step in the gluing process, other methods must be implemented. Usually a «cold» de-greasing process is used, which involves rubbing the surfaces with a solvent. Most solvents cannot be used in arctic conditions.

The main property of solvents is their ability to dissolve various compounds. In freezing conditions most solvent's capabilities are greatly decreased. Common solvents such as gasoline and Stoddard solvent become very «weak» at temperatures below 0 centigrade. Better alternatives are P-4 and P-5 solvents. The main difference between these solvents is the percent content of acetone and butyl acetic ether. P-4 solvent contains no more than $12 \%$ butyl acetic ether and P-5 contains no more than $10 \%$

For the fastest drying of solvents on working surfaces (especially various nooks and crannies) solvents must be able to evaporate quickly. This parameter at freezing temperatures is determined by the solvent's saturated steam pressure.

One must take into account that the aforementioned solvents can be stored at -30 degrees centigrade, but their use is only possible at no less than 15 degrees centigrade.

The next step in the gluing process is the preparation of the glue. As mentioned in chart 3 , some procedures can onl be carried out with certain limitations. For example - in 
freezing temperatures only a certain ammount of glue can be mixed together while retaining its properties (approx. 100-150 grams). A larger quantity of glue would require longer mixing times which in turn will result in a lower glue viscosity. Mixing should not take more than a few minutes.

When applying the glue at below freezing temperatures it is important to take into account surface tension and the resulting angle of application $(\theta)$.

When the angle of application is $\theta>90^{\circ}$ (Fig. 1-a), the glue will not spread out on it's own. When the angle is $\theta<90^{\circ}$, then glue will spread out unassisted. If the glue fully spreads out on it's own the angle value is equal to 0 . The spread angle (usually defined as $\cos \theta)$ depends on the temperature $(\mathrm{T})$ and time $(\mathrm{t})$

$$
\cos \theta=f(T, t)
$$

This equation applies to thermo-active glues which can reach these specifications when they spread.

When the spread angle is close to 1-2 degrees, the glue begins to leak out of crevices and seams which leads to poor quality seals. When the angle is close to 180 degrees, the opposite happens. The glue does not cover the entire working area. The optimal spread angle for freezing temperatures is $20-40$ degrees. This angle can be acheived by selecting the correct glues for specific materials whilst taking into account the polarity of both the glue and the material.

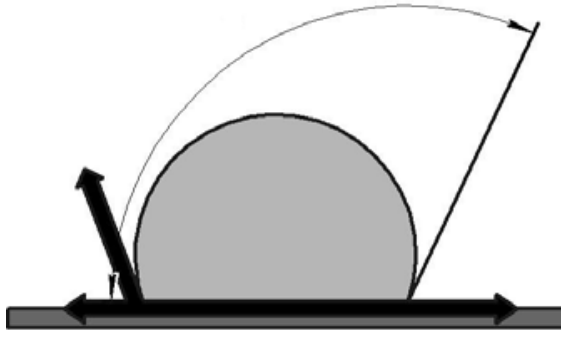

a)

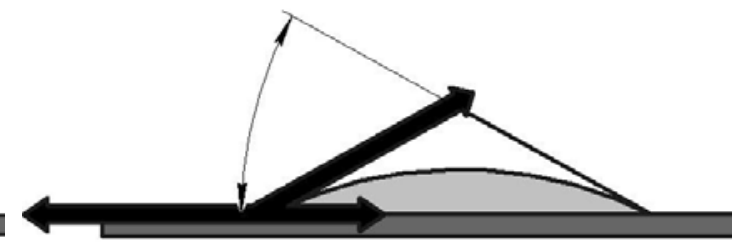

b)

Fig. 1. Glue drop on a hard surface with different contact angle $\theta>90^{\circ}$ (a) and $\theta<90^{\circ}$ (b)

When applying glue by hand it is difficult to attain an even layer at room temperature even if you are highly skilled. Freezing temperatures cause rapid changes in the glue's viscosity. This problem can be solved by adding various modifying compounds to the glue. These compounds not only normalize the changes in viscosity, but also aid in the curing of glue.

Many difficulties arise during the joining of parts in below zero temperatures. A decrease in temperature causes shrinkage in various materials which can lead to inconsistencies during assembly. Another big problem is frost formation which leads to poor adhesion between surfaces. Special equipment is required to overcome these problems.

Curing is one of the most important final steps of gluing. Low temperatures cause longer curing times. Usually at temperatures below 5 degrees centigrade most glues don't cure fully. This can be solved with the use of hardening agents.

Other problems arise when technologies such as glue welding and glue riveting are used. Glue welding is difficult because it requires additional equipment when implemented in below freezing temperatures. Glue riveting is also very limited due to metals becoming more brittle at lower temperatures. 
An important factor in the glue repair process is quality control, which consists of three steps: The control of materials, control of the process and final product quality control.

Inaccordance with the government standard 30535-97, quality control for glued materials is carried out visually. The main observed parameters are $[9,10]$ :

- Equality of gap sizes.

- Signs of glue deformation.

- Hardness of the glue.

If these requirements are not met, negative consequences such as excessive elasticity or excessive brittleness can occur. Errors during each of the gluing process steps can be corrected in order to avoid additional costs and failures if proper quality control is administered. Table 4 demonstrates the main steps that need to be taken to repair cracks with the use of polymer materials.

Table 4. The list of properties monitored on basic technological repair stages

\begin{tabular}{|c|c|c|}
\hline Basic technological stages & Monitored properties & Possible defects \\
\hline $\begin{array}{l}\text { Surface preparation to quality } \\
\text { control }\end{array}$ & Surface cleanliness & $\begin{array}{l}\text { Quality control faults (false } \\
\text { damage location) }\end{array}$ \\
\hline Quality control & $\begin{array}{l}\text { Damage dimensions and } \\
\text { margins }\end{array}$ & Wrong repair technology \\
\hline $\begin{array}{l}\text { Repair zone chemical } \\
\text { treatment }\end{array}$ & $\begin{array}{l}\text { Surface cleanliness (no dirt, } \\
\text { peelable particles, oil, gasoline } \\
\text { or grease stains) }\end{array}$ & Lack of adhesion \\
\hline Glue selection & $\begin{array}{l}\text { Glue's technological, physical } \\
\text { and mechanical properties, } \\
\text { compliance to GOST } \\
\text { (Government Standard), TU } \\
\text { (Technical Requirements), } \\
\text { repaired surface and } \\
\text { environmental conditions }\end{array}$ & Reduced adhesion strength \\
\hline Application of glue & $\begin{array}{l}\text { Glue's technological, physical } \\
\text { and mechanical properties, } \\
\text { compliance to GOST } \\
\text { (government standard), TU } \\
\text { (Technical Requirements), } \\
\text { repaired surface and } \\
\text { environmental conditions }\end{array}$ & $\begin{array}{l}\text { Increase of glue viscosity } \\
\text { during the application } \\
\text { process, uneven seam, lack of } \\
\text { adhesion }\end{array}$ \\
\hline Polymerization & $\begin{array}{l}\text { Polymerization, air humidity, } \\
\text { curing time, applied load }\end{array}$ & $\begin{array}{l}\text { Layering and cracking or } \\
\text { seam brittleness, reduced } \\
\text { adhesion }\end{array}$ \\
\hline Mechanical treatment & $\begin{array}{l}\text { Glue deformation, cured glue } \\
\text { hardness }\end{array}$ & $\begin{array}{l}\text { Excessive elasticity or by } \\
\text { contrast excessive seam } \\
\text { brittleness }\end{array}$ \\
\hline
\end{tabular}

Quality control is imperative for proper repair work and the elimination of future defects in the materials being glued.

The process of gluing materials in arctic conditions requires the development of technological programs which differentiate depending on temperature readings. It's well known that the arctic regions are very different when it comes to absolute and average temperature readings. For example the Whalen region does not record temperatures lower than -45 degrees centigrade, while zones in the antarctic pool record temperatures of -52 degrees centigrade. An even bigger difference can be seen in these region's average monthly temperatures $(+5.5$ and -0.2 degrees centigrade respectively.

Because of such differences, technological programs must be adapted for average temperatures. 
The classification of technological processes must be differentiated by the outside temperature readings. The factors in this classification will include viscosity, curing times, solvent usability, hardness of glues. It is also important to classify different materials that are to be glued.

The standartisation of technological processes will enable the unification of gluing technologies, which in turn will lead to reduced working costs, ease of application and high quality of work for the repair of components and systems in the field.

\section{References}

1. A. Yu. Konoplin, N. I. Baurova, Hardness of the Near-Weld Zone during Contact Spot Welding of Steels Using an Adhesive-Weld Technology, Russian Metallurgy, v.13, pp. 1308-1311 (2016).

2. V.V. Grib, V.A. Zorin, R.V. Zukov, Multicriteria assessment of the theoretical state of mechanisms and machines, Repair, recovery, modernization, v.6, pp. 19-22 (2016).

3. N.I. Baurova, A.Y. Sergeev, Application of differential-scanning calorimetry for studying the properties of filled adhesive materials, Polymer Science - Series D, v.7(2), pp. 140-144. (2014).

4. V.A. Nelyub, A.S. Borodulin, L.P. Kobets, G.V. Malysheva, Capillary hydrodynamics of oligomer binders, Polymer Science - Series D, v.9(3), pp. $322-332$ (2016).

5. A. Yu. Konoplin, N.I. Baurova A study of the properties and microstructure of weldbonded joints, Polymer Science - Series D, v.9(1), pp. 1-4 (2016).

6. N.V. Lapina, Methods and standards for determining the frost resistance of polymeric materials, Vse materialy. Encyclopedic reference book, v.2, pp. 65-69 (2017).

7. G.V. Malysheva, M.V. Shablygin, T.A. Guzeva, Method for Assessing Aramide Fiber Microstructure Features, Fibre Chemistry, v.47(2), pp. 85-88 (2015).

8. V.M. Prikhodko, V.A. Aleksandrov, D.S. Fatyukhin, L.G. Petrova, Effect of ultrasonic cavitation on nitride steel surface laver condition, Metal Science and Heat Treatment, v.57(5-6), pp. 300-303 (2015).

9. A.K. Shvedkova, A.P. Petrova, V.M. Buznik, Climatic stability of composite materials based on adhesive prepregs in the Arctic, Glue. Sealants. Technologies, v.1, pp. 19-24 (2016).

10. A.P. Petrova,. I.A. Sharova, N.F. Lukina, V.M. Buznik, The possibility of applying adhesives in Arctic conditions, Glue. Sealants. Technologies, v.7, pp.10-15 (2015). 